\title{
Experimental Approach to a Role of the Increased T-Kininogen Level in Carrageenin-Induced Pleurisy of Rats
}

\author{
Sachiko OH-ISHI, Naoki TSUJI and Izumi HAYASHI \\ Department of Pharmacology. School of Pharmaceutical Sciences. \\ Kitasato University, 5-9-1 Shirokane, Minato-ku, Tokyo 108, Japan
}

Accepted January 19, 1989

\begin{abstract}
In order to elucidate the biological role of T-kininogen, it's levels in plasma, exudate, and liver were measured by radioimmunoassay in rats following the induction of carrageenin pleurisy. T-kininogen level in the liver microsomes was increased markedly at 8-24 hr after the carrageenin injection, and its plasma level increased at 24-48 hr with a delay. Pretreatment with dexamethasone suppressed the pleural exudate accumulation almost completely, but inhibited the T-kininogen level in plasma or liver only partially. When rats were pretreated with carrageenin injection into a paw 2 days prior to intrapleural injection of carrageenin, the pretreatment did not affect the pleurisy development, even though the plasma level of $\mathrm{T}$ kininogen was greatly increased. Increased level of T-kininogen correlated well with the thiol protease inhibitor activity found in the plasma and exudate. These results indicate that an increase in the T-kininogen level does not influence the exudation, but might act as an inhibitor of thiol proteases that could be released at the inflammatory site.
\end{abstract}

T-kininogen has a bradykinin moiety and thiol protease inhibitor region in its primary structure $(1-3)$. It was reported to be an acute phase reactant in rats and its plasma level increases after inflammatory stimuli and lesion (4-7). Among these studies, Barlas et al. reported that plasma $T$-kininogen level was increased in parallel with paw swelling following Freund's adjuvant treatment (7). Our previous experiments demonstrated that $T$ kininogen was found in the plasma of HMWand LMW-kininogens deficient rats (Brown Norway Katholiek strain) and that the level was increased after turpentine and carrageenin injection in a similar manner as in normal strain animals (6). However, the deficient strain showed less reactivity to carrageenin-induced inflammation. Therefore we assumed that HMW-kininogen was responsible for the inflammatory reaction, but T-kinninogen was not involved. The present study was undertaken to determine whether T-kininogen works as an anti-inflammatory or pro-inflammatory agent when it's level is increased by inflammatory stimuli. For its quantification, we measured T-kininogen by a specific radioimmunoassay that we had previously developed (8).

\section{Materials and Methods}

Induction of pleurisy: Male 7-week-old Sprague-Dawley rats were purchased from Shizuoka Experimental Animal Center (Hamamatsu). The series of experiments on rat pleurisy were done as previously reported (9). Pleurisy was induced by the intrapleural injection of $0.1 \mathrm{ml}$ of $2 \%$ carrageenin (Sigma). When used, dexamethasone (Sigma) was dissolved in ethyl alcohol $(10 \mathrm{mg} / 0.5 \mathrm{ml})$, diluted in physiological saline $(0.5 \mathrm{mg} / \mathrm{ml})$. and then injected intraperitoneally into rats 2 hr prior to the carrageenin injection. Control rats received vehicle only and were otherwise treated in the same manner.

Measurement of $\mathbf{T}$-kininogen and protein content: T-kininogen contents in the plasma. and liver microsomal fraction were measured by a specific radioimmunoassay using monoclonal antibody to T-kininogen as previously described $(8,10)$. Purified T- 
kininogen was a gift from Dr. H. Kato and Mr. K. Enjyoji (National Cardiovascular Center Research Institute. Osaka) and Dr. S. Iwanaga (Kyushu University) $(11,12)$. 125l-Labelled T-kininogen was prepared as previously reported (8). Protein was measured by the method of Lowry et al. (13).

Liver microsomal fraction preparation and assay: The livers were perfused with approximately $15 \mathrm{ml}$ of Tyrode's solution through the portal vein and homogenized as previously reported (7). T-kininogen content was assayed by RIA (8).

Thiol protease inhibitor activity: Papain (Sigma), $25 \mathrm{ng}$, was preincubated at $30^{\circ} \mathrm{C}$ for $10 \mathrm{~min}$ in $1 \mathrm{~m}$ ! of $0.4 \mathrm{M}$ sodium acetate buffer, $\mathrm{pH} 7.5$, containing $4 \mathrm{mM}$ EDTA-2Na. $0.01 \%$ gelatin and $1 \mathrm{mM}$ cysteine; and then rat plasma or exudate was added, and the mixture was incubated at $37^{\circ} \mathrm{C}$ for $10 \mathrm{~min}$. The remaining thiol protease activity was then assessed by the production of fluorescence after incubation with Z-phe-arg-MCA (Peptide Institute, Minoh) (14).

Elimination of T-kininogen in blood: 1251 T-kininogen (1 $\left./ \mathrm{g} .10^{6} \mathrm{cpm}\right)$ was injected into the tail vein of rats, and a blood sample was collected from the brachial vein or tail vein under light ether anesthesia at the indicated time. The ha!f life of each elimination curve was calculated using the two compartment model.

Statistical analysis: Statistical analyses were carried out by Student's $t$-test at $\mathrm{P}$ 0.05 or $P<0.01$.

\section{Results}

Time course of rat pleurisy and T-kininogen levels: Figure 1 shows the time course of carrageenin induced rat pleurisy. As shown in panel A. pleural fluid accumulation peaked at $16 \mathrm{hr}$ after the carrageenin injection, and it gradually decreased until the value was around $1 \mathrm{ml}$ at $96 \mathrm{hr}$. Leukocyte migration into the exudate took place later than the exudate formation, and the peak was observed at $24 \mathrm{hr}$. Classification of leukocytes indicated that PMN leukocytes migrated earlier, and then later, monocytes increased in number in the exudate.

Figure 2 indicates $T$-kininogen levels in the plasma, exudate, and liver during the pleurisy.

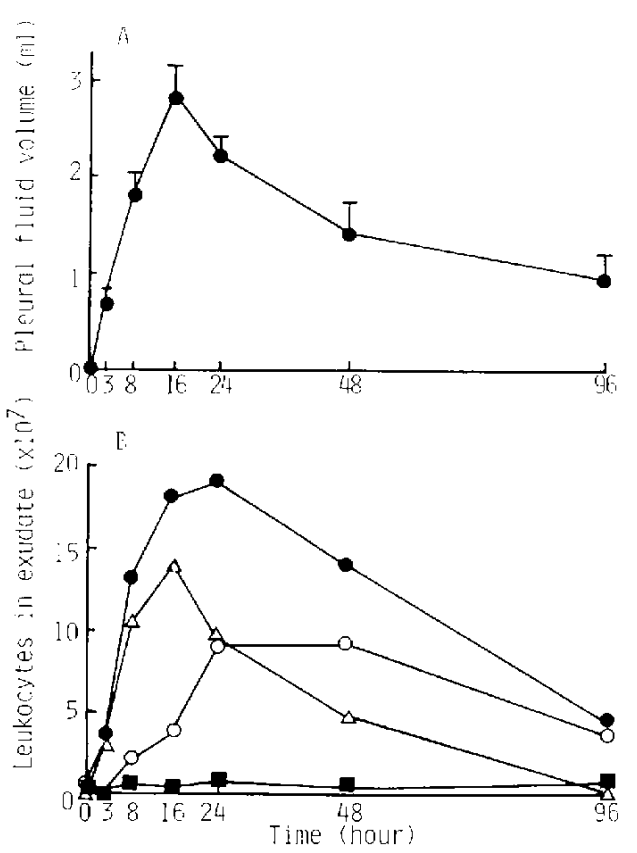

Fig. 1. Time course of pleural exudate accumulation (A) and migrated leukocytes in the exudate (B) during carrageenin-induced rat pleurisy. Values indicated by closed circles are the means of $6-8$ rats with standard errors $(A)$. Classification of leukocytes was determined under a light microscope using a Giemsa stained pleural exudate film. Total leukocytes $(-\infty)$. PMN leukocytes $(-\triangle \rightarrow$ ) and monocytes $(-\bigcirc-)$. Mast cells and eosinophils are classified into one group. which was indicated as "others $(-\square--)^{\prime \prime}$.

The level in the plasma slowly increased up to $24 \mathrm{hr}$ after carrageenin injection, and the peak level was about $6-7$ fold over the control level. By $96 \mathrm{hr}$, the level had decreased, but was still 3 times higher than the control level. The T-kininogen level in the pleural exudate also increased, with kinetics similar to but slightly slower than that in plasma. Protein concentration in the pleural fluid increased rapidly at 3-8 hr and then stayed almost constant. The level in the liver increased slightly faster than the level in plasma, indicating that the synthesis may take place in the liver following the inflammatory stimulus.

Effect of pretreatment with dexamethasone: Dexamethasone at a dose of $0.5 \mathrm{mg} / \mathrm{kg}$ was injected intraperitoneally $2 \mathrm{hr}$ before the carrageenin. Pleurisy at $16 \mathrm{hr}$ after the car- 

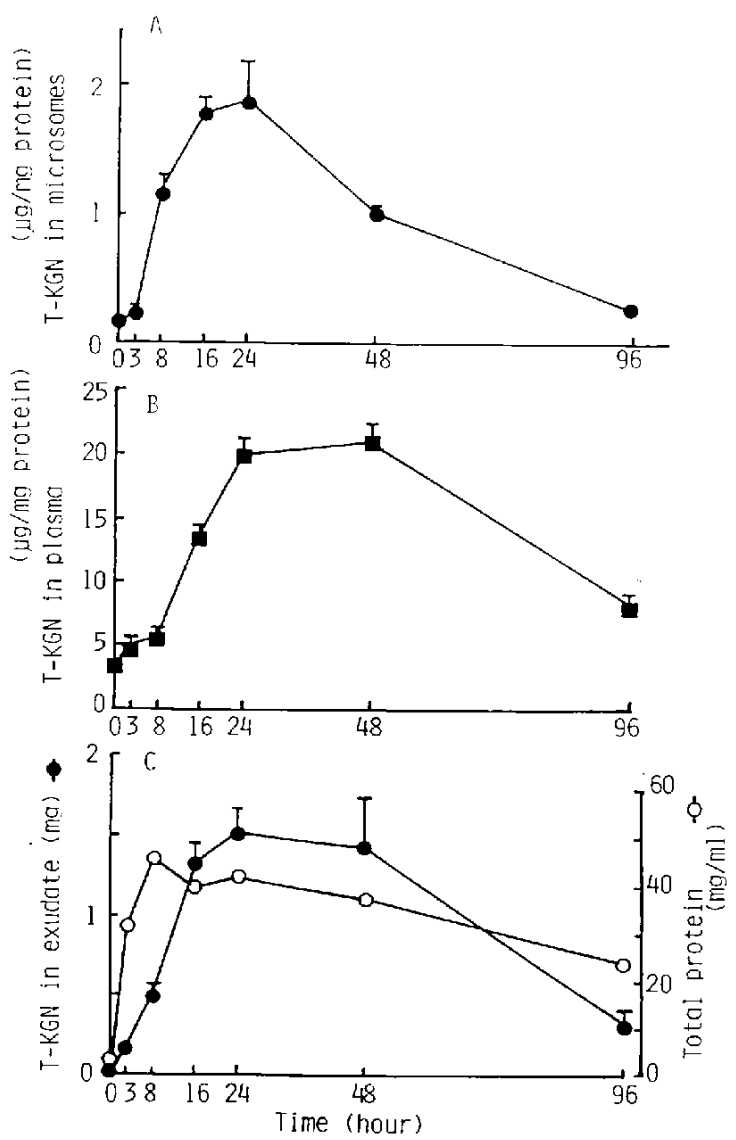

Fig. 2. T-kininogen levels in liver microsomes (A). plasma (B) and pleural exudate (C) during carrageenin-induced pleurisy. T-kininogen levels were determined by RIA and calculated as $\mathrm{ng} / \mathrm{mg}$ protein. Values are means with standard errors from $6-8$ rats as shown in Fig. 1. Total protein in the exudate (-O-) is shown in panel $C$.

rageenin was examined as illustrated in Fig. 3. The accumulation of pleural fluid was completely suppressed and cell migration was significantly decreased. T-kininogen levels in the plasma and liver were significantly but not completely decreased by the pretreatment.

Effect of pretreatment with carrageenin: This experiment was undertaken to see if the increased $T$-kininogen level would affect the development of pleurisy. T-kininogen plasma level was increased following the carrageenin injection at the paw, and it was $13 \pm 2$ and $11 \pm 1(\mu \mathrm{g} / \mathrm{mg}$ protein with standard error) at $48 \mathrm{hr}$ and $72 \mathrm{hr}$, respectively. Then the level increased further after the second injection of carrageenin: about 27 and $50 \mu \mathrm{g} / \mathrm{mg}$ of $C G+C G 3 h$ and $C G+C G 16 h$, respectively, in Fig. 4. As shown in Fig. 4, pretreatment with $1 \%$ carrageenin $10.1 \mathrm{ml}$ into a paw 2 days before the pleural injection of carrageenin) had no significant effect on pleural fluid accumulation or on leukocyte counts in the exudates at $3 \mathrm{hr}$ and $16 \mathrm{hr}$.

Effect of pretreatment with bromelain: Bromelain injection into rats was previously reported to deplete HMW-kininogen and to decrease carrageenin pleurisy at $3 \mathrm{hr}$ (15). The treatment decreased exudation significantly even at $16 \mathrm{hr}$ of pleurisy, but the $\mathrm{T}$ kininogen level increased after carrageenin injection with or without bromelain pretreatment (Fig. 5)

Elimination of T-kininogen from rat plasma: Elimination of 125 -T-kininogen from plasma was examined in normal and inflamed rats. The latter rats received intrapleural carrageenin $16 \mathrm{hr}$ before the sample collection. The half lives of $125 /$-T-kininogen levels in plasma with standard errors were $27.5 \pm 1.1$ hr $(n=4)$ for normal rats and $26.7 \pm 1.4(n=4)$ $\mathrm{hr}$ for the inflamed ones.

Thiol protease inhibitor activity: Thiol protease-inhibiting activity of the plasma and of the inflammatory exudate of these pleurisies were measured by the remaining amidase activity of papain. Figure 6 shows the relationships of T-kininogen level in plasma (A) and pleural exudate (B) to the inhibitor activity. All data of pleurisy at $3 \mathrm{hr}$ to $16 \mathrm{hr}$ were plotted. Correlation coefficients of the inhibitory activity against T-kininogen levels of plasma and of the exudate were 0.96 and 0.88 , at $P<0.05$. with slopes of 0.48 and 0.39 , respectively.

\section{Discussion}

The time course of carrageenin-induced pleurisy was mostly similar to that reported by Uchida et al. (16). As reported previously (8. 10), the increased T-kininogen level in plasma of rats receiving inflammatory stimuli could be caused by increased synthesis of this protein in the liver, since the liver level increased faster than the plasma level, as shown in Fig. 2. Plasma elimination of $\mathrm{T}$ kininogen in inflamed rats was not signifi- 

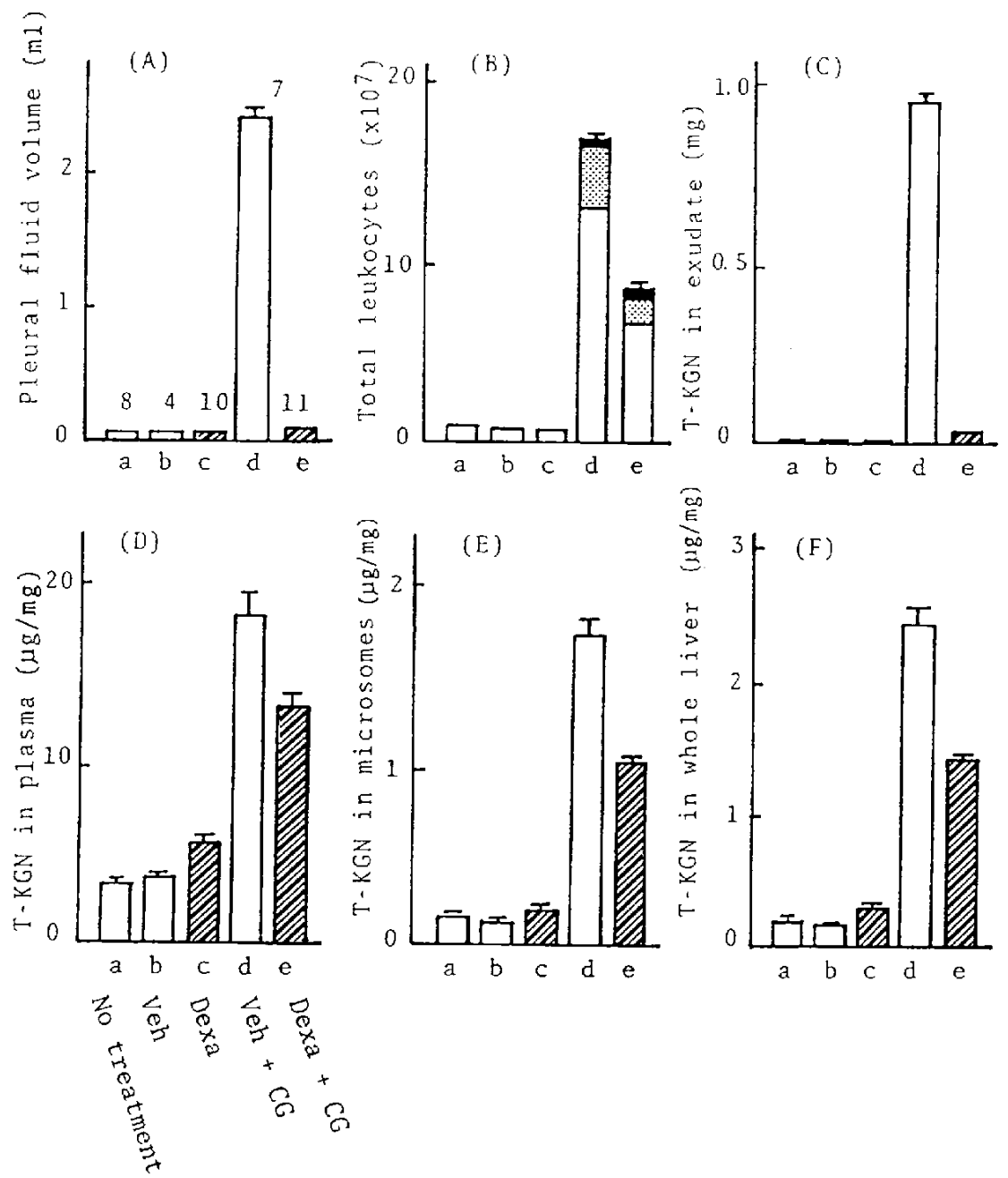

Fig. 3. Effect of pretreatment with dexamethasone on rat pleurisy and on the levels of T-kininogen. (A) Pleural fluid volume ( $\mathrm{ml}$ ); (B) Total number of leukocytes in pleural exudate $\left(\times 10^{7}\right)$ and classification of leukocytes: polymorphonuclear leukocytes $\square$, monocytes 5 and others $\square$ : (C) Total T-kininogen amount in the exudate (mg): (D) T-kininogen level in plasma ( $\mu \mathrm{g} / \mathrm{mg}$ protein): (E) T-kininogen content in liver microsomal fraction ( $\mu \mathrm{g} / \mathrm{mg}$ protein); and $(\mathrm{F}) \mathrm{T}$-kininogen amount in whole liver homogenate $(\mu \mathrm{g} /$ $\mathrm{mg}$ prote $(n)$. Rats were divided into 5 groups and numbers of rats used are shown by the figures by the columns in panel (A): $a$, untreated control group; $b$, group receiving intraperitoneal vehicle injection $(2.5 \%$ ethanol, $1 \mathrm{ml} / \mathrm{kg}$ ) at $18 \mathrm{hr}$ before the sacrifice; c, group receiving intraperitoneal dexamethasone in $2.5 \%$ ethanol. $0.5 \mathrm{mg} / \mathrm{kg}$. at $18 \mathrm{hr}$ before the sacrifice: d. group sacrificed at $16 \mathrm{hr}$ after intrapleural injection of $0.1 \mathrm{ml}$ of $2 \%$ carrageenin solution which was preceded $2 \mathrm{hr}$ earlier by an injection of $2.5 \%$ ethanol as a vehicle; e, group sacrificed at $16 \mathrm{hr}$ after the carrageenin injection which was preceded $2 \mathrm{hr}$ earlier by an intraperitoneal injection of $0.5 \mathrm{mg} / \mathrm{kg}$ dexamethasone.

cantly different from that of normal rats, indicating that the increased level was not caused by diminished catabolism of $T$ kininogen. T-kininogen level in the pleural exudate also increased following the plasma level increase, indicating that plasma protein exudation occurred throughout the time course of this pleurisy.

Dexamethasone almost completely suppressed the pleurisy and significantly but 

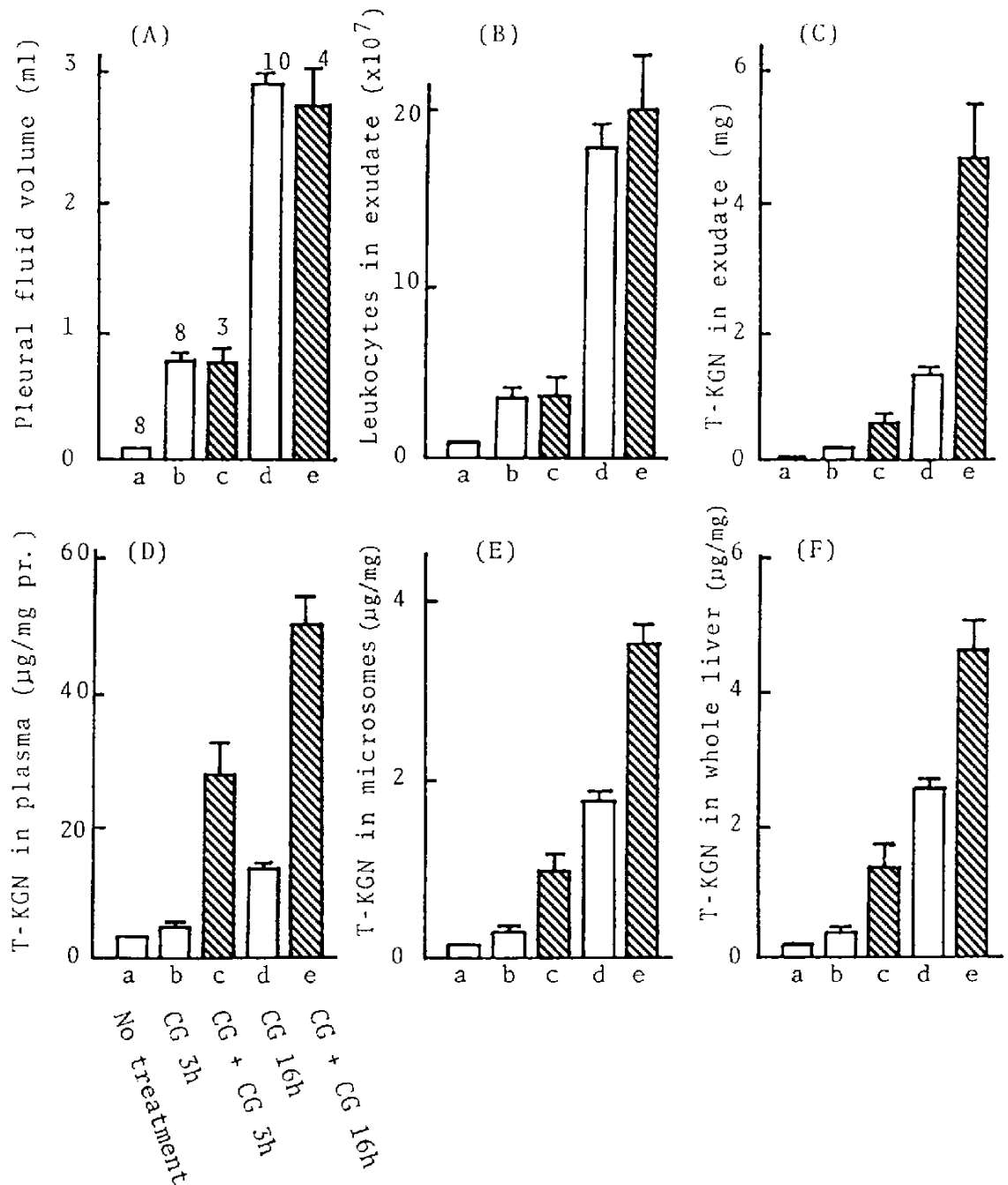

Fig. 4. Effect of pretreatment with carrageenin on the development of pleurisy and T-kininogen levels. Panels (A) to (F) indicate the same parameters examined as those in Fig. 3. Rats are in 5 groups, and numbers used are shown at the tops of the columns in panel (A). Group a. untreated control; $b$, sacrificed at $3 \mathrm{hr}$ of carrageenin pleurisy without pretreatment; c. carrageenin pleurisy at $3 \mathrm{hr}$ with pretreatment of intradermal carrageenin injection into a paw 2 days before the initiation of pleurisy; $d$, carrageenin pleurisy at $16 \mathrm{hr}$ without pretreatment; and e, carrageenin pleurisy at $16 \mathrm{hr}$ with the pretreatment of intradermal carrageenin injected into a paw 2 days prior to the initiation of the pleurisy.

partly decreased the T-kininogen levels in the plasma and liver, as shown in Fig. 3. Barlas et al. reported that inhibitory effects of dexamethasone and indomethacin on paw swelling induced by the adjuvant was parallel with the reduction of T-kininogen level (7). This was not the case in our studies, and we have to consider multiple actions of dexamethasone on the defense reaction. One of the anti-inflammatory effects of dexamethasone is known to be its production of anti-phospholipase protein to suppress arachidonate metabolites production (17). Another mode of action of dexamethasone may cause a partial suppression of T-kininogen level by inhibiting the production of cytokine which has been suggested to be a mediator for hepatic induction of T-kininogen synthesis (18). 

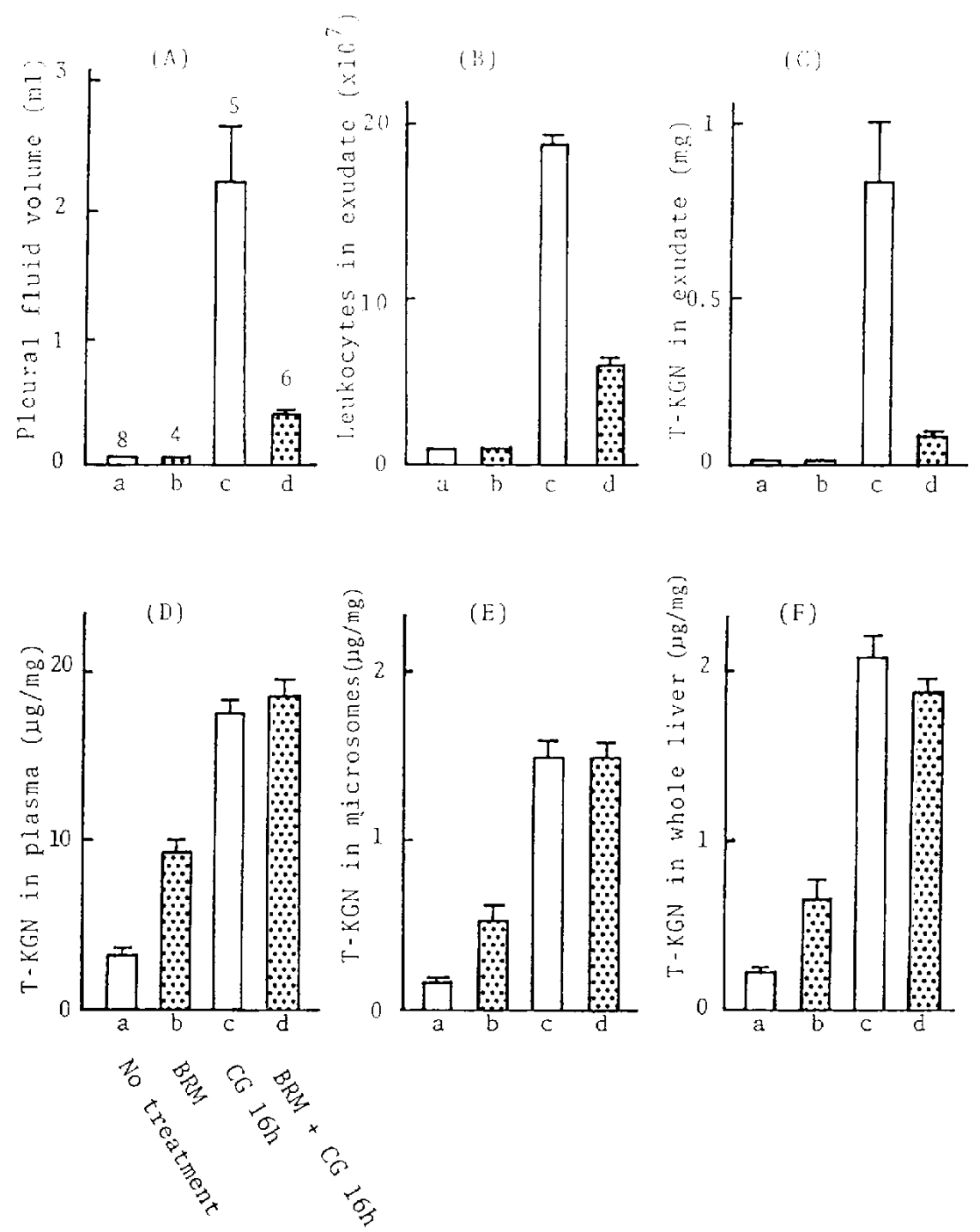

Fig. 5. Effect of bramelain injection on carrageenin-induced pleurisy. Panels $(A)$ to (F) are the same as those in Fig. 3. Rats were divided into 4 groups and numbers of rats used are shown at the tops of the columns in panel (A). Group a. untreated control group: b. a group receiving only $10 \mathrm{mg} / \mathrm{kg} \mathrm{bromelain}$. intravenously, at $16.5 \mathrm{hr}$ before the sacrifice; c, carrageenin-induced pleurisy at $16 \mathrm{hr}$; and d. carrageenininduced pleurisy with bromelain pretreatment $30 \mathrm{~min}$ before the carrageenm injection.

We tried to determine if an increased $T$ kininogen level might work as an anti-inflammatory agent, since some counter irritants have been used for treatment of inflammation (19). As shown in Fig. 2, pretreatment with inflammatory stimuli such as carrageenin caused a marked increase in T-kininogen level. However, the increased level of $T$ kininogen does not appear to cause sup- pression of pleural exudation, since no inhibition was observed with carrageenin pretreatment up to $16 \mathrm{hr}$ (Fig. 4). Therefore the increased level of $T$-kininogen does not directly account for the counter irritant effect. Furthermore, the pretreatment with bromelain resulted in marked suppression of exudation at $16 \mathrm{hr}$ in the same way as that at $3 \mathrm{hr}$. which was previously reported (15). However, 
(A)

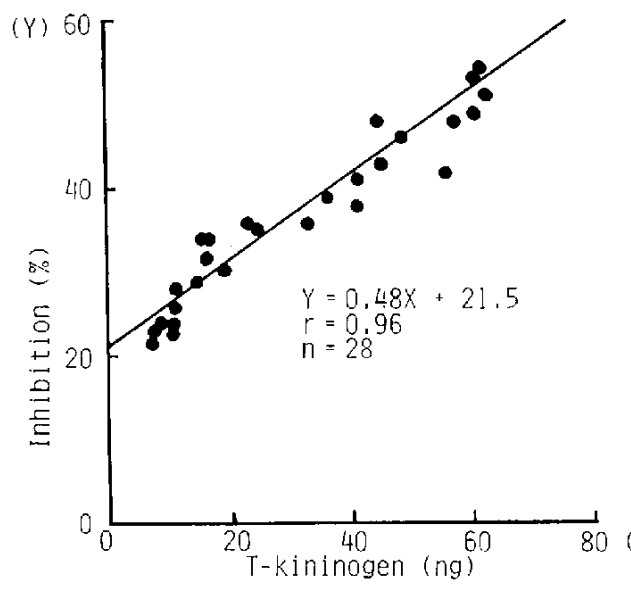

(B)

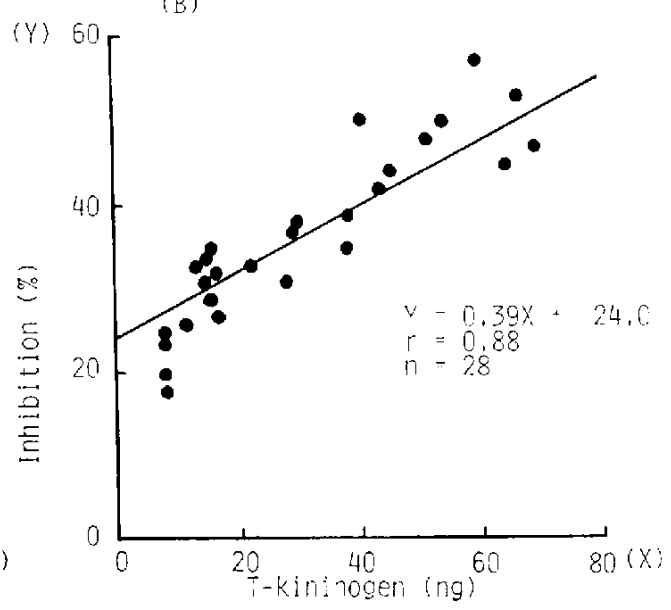

Fig. 6. Relationship of thiolprotease inhibitor activity to $T$-kininogen levels in plasma (A) and pleural exudate $(B)$ among various samples of carrageenin-induced pleurisy.

bromelain pretreatment did not have any significant effect on the increased level of $T$ kininogen after carrageenin injection. In other words, the plasma T-kininogen level of carrageenin-treated rats and rats pretreated with bromelain were similar, while the former animals showed marked pleural exudation. and the latter had less exudate formation. These results coincide well with those given in our previous report, in which the time course of paw edema swelling preceded the increase in T-kininogen level, thus leading us to conclude that $T$-kininogen played no role in exudation: i.e., it was not involved in either proinflammatory or anti-inflammatory action (9).

Kininogen are reported to possess thiol protease inhibitory activity (14) since the binding sites for thiol proteases have been demonstrated in their sequences (20). Therefore we can expect that T-kininogen might work to inhibit enzymes involved in inflammatory process. Figure 6 demonstrates clearly that the inhibitory activity against papain increased linearly with the content of $T$ kininogen in plasma or exudate. Thus a close relationship exists between the inhibitory activity and T-kininogen level. Furthermore, the slope of the activity in the exudate showed a slight decay, indicating that $T$-kininogen in the exudate is less active: i.e., a part of the T-kininogen in the exudate might be bound or degraded by an enzyme(s) in the exudate. Our result could not show any direct evidence for the anti-inflammatory character of $T$ kininogen even with its potent protease inhibitory effect. However, it may affect later defense mechanisms of body such as the immune activity. etc. Elucidation of this relationship remains for a future study

Acknowledgments: This work was partly supported ty the Naito Foundation and a Grant-in-Aid for Scientific Research (61304064) from the Ministry of Education. Science and Culture, Japan.

\section{References}

1 Okamoto, H. and Greenbaum, L.M.: Kininogen substrates for trypsin and catepsin D in human. rabbit and rat plasmas. Life Sci. 32, 2007-2013 (1983)

2 Furuto-Kato, S., Matsumoto, A., Kitamura, N. and Nakanishi, S.: Primary structures of the mRNAs encoding the rat precursors for bradykinin and T-kinin. J. Biol. Chem. 260, 1205412059 (1985)

3 Anderson, K.P. and Heath, E.C.: The relationship between rat major acute phase protein and the kinınogens. J. Biol. Chem. 260, 12065-12071 (1985)

4 Damas, J. and Adam, A.: The Brown Norway deficient rat as a tool for the study of the involvement of the kinin system in some physiological processes. In Marker Proteins in Inflammation. Edited by Bienvenu, J., Grimaud, J.A. and Laurent, P., Vol. 3, p. 265-274, Walter de 
Gruyter, Berlin (1986)

$5 \mathrm{Koj}$. A.: Definition and classification of acutephase proteins. In The Acute Phase Response to Injury and Infection, Edited by Gordon, A.H. and Koj, A., p. 139-144, Elsevier, Amsterdam (1985)

6 Hayashi, 1., Oh-ishi, S., Kato, H., Enjyoji, K., Iwanaga, $S$. and Nakano, T.: Identification of $T$ kininogen in high and low molecular weight kininogens deficient rat (Brown Norway Katholiek strain). Thromb. Res. 39, 313-321 (1985)

7 Barlas, A., Okamoto, H. and Greenbaum, L.M.: T-kininogen-The major plasma kininogen in rat adjuvant arthritis. Biochem. Biophys. Res. Commun. 129, 280-286 (1985)

8 Hayashi, I., Oh-ishi, S., Enjyoji, K., Kato, H. and Iwanaga, S.: A radioimmunoassay for rat $T$ kininogen as an acute phase reactant. Chem. Pharm. Bull. (Tokyo) 34, 3502-3505 (1986)

9 Oh-ishi, S., Hayashi, I., Hayashi, M., Yamaki, K., Yamasu, A., Nakano, T., Utsunomiya, I. and Nagashima, Y.: Evidence for a role of the plasma kallikrein-kinin system in acute inflammation: reduced exudation during carrageenin- and kaolin-pleurisies in kininogen-deficient rats. Agents Actions 18, 450-454 (1986)

10 Utsunomiya, I., Oh-ishi, S., Hayashi, I., Maruhashi, J., Tsuji, N., Yamamoto, N. and Yamashina, S.: Monoclonal antibodies against rat $\mathrm{T}$ kininogen: Application to radioimmunoassay and immunohistochemistry. J. Biochem. (Tokyo) 103, 225-230 (1988)

11 Enjyoji, K., Kato, H., Hayashi, I., Oh-ishi, S. and Iwanaga, S.: Purification and characterization of two kinds of low molecular weight kininogens from rat (non-inflamed) plasma. J. Biol. Chem. 263, 965-972 (1988)

12 Enjyoji, K., Kato, H., Hayashi, 1., Oh-ishi, S. and Iwanaga, S.: Purification and characterization of rat T-kininogen isolated from plasma of adjuvant-treated rats. J. Biol. Chem. 263, 973-
979 (1988)

13 Lowry, O.H., Rosebrough, N.J., Farr, A.L. and Randall, R.J.: Protein measurement with the Folin phenol reagent. J. Biol. Chem. 193, 265275 (1951)

14 Sueyoshi, T., Enjyoji, K., Shimada, T., Kato, H., Iwanaga, S., Bando, Y., Kominami, E. and Katsunuma, $\mathbf{N}$ : : A new function of kininogens as thiol-protease inhibitors: Inhibition of papain and cathepsins $B . H$ and $L$ by bovine, rat and human plasma kininogens. FEBS Lett. 182, 193-195 (1985)

15 Oh-ishi, S., Uchida, Y., Ueno, A. and Katori, M.: Bromelain, a thiolprotease from pineapple stem. depletes high molecular weight kininogens by activation of Hageman factor (Factor XII). Thromb. Res. 14, 665-672 (1979)

16 Uchida, Y., Tanaka, K., Harada, Y., Ueno, A. and Katori, M.: Activation of plasma kallikrein-kinin system and its significant role in pleural fluid accumulation of rat carrageenin-induced pleurisy. Inflammation 7.121-131 (1983)

17 Flower, R.J. and Blackwell, G.J.: Anti-inflammatory steroids induce biosynthesis of a phospholipase $A_{2}$ inhibitor which prevents prostaglandin generation. Nature 278, 456-459 (1976)

18 Ito, N., Yayama, K. and Okamoto, H.: Stimulation of hepatic T-kininogen production by interferon. FEBS Lett. 229, 247-250 (1988)

19 Smith, M.J.H. and Ford-Hutchinson, A.W.: Anti-inflammatory agents of animal origin. In Anti-Inflammatory Drugs, Edited by Vane. J.R. and Ferreira. S.H.. p. 661-697. Springer-Verlag. Berlin (1979)

20 Kitagawa, H., Kitamura, N., Hayashida, H., Miyata, T. and Nakanishi, S.: Differing expression patterns and evolution of the rat kininogen gene family. J. Biol. Chem. 262, 2190-2198 (1987) 